\title{
It all started with a clubfoot: Beliefs surrounding cerebral palsy throughout history
}

\author{
Kristina M. Stang ${ }^{\mathrm{a}, *}$, Nicholas E. King ${ }^{\mathrm{b}}$ and Deborah Gaebler-Spira ${ }^{\mathrm{c}}$ \\ ${ }^{a}$ Tulane University School of Medicine, New Orleans, LA, USA \\ ${ }^{\mathrm{b}}$ University of Texas Health Sciences Center at Houston, Houston, TX, USA \\ ${ }^{\mathrm{c}}$ Department of Physical Medicine and Rehabilitation and Pediatrics, Feinberg Northwestern School of Medicine, \\ Rehabilitation Institute of Chicago, Chicago, IL, USA
}

Keywords: Pediatrics, cerebral palsy, medical history, Little's Disease

Over 1000 years before the beginning of the common era, the kingdom of Egypt was expanding from the banks of the Nile. The Egyptians' wealth and belief in the afterlife led them to construct elaborate tombs. From the $16^{\text {th }}$ to $11^{\text {th }}$ century BCE, tombs were excavated for pharaohs and powerful nobles of the New Kingdom - the $18^{\text {th }}$ to $20^{\text {th }}$ dynasties of Ancient Egypt - in the Valley of Kings, located on the west bank of the Nile opposite Thebes. Of the more than 60 tombs discovered there, the tomb KV-47 yielded a surprise: a boy pharaoh with an equinovarus foot (i.e. clubfoot) deformity who died at the age of 20, tell-tale signs of cerebral palsy (CP). This boy, the Pharaoh Siptah, is one of the oldest examples of a physical disability that has affected children since antiquity [1-3].

Cerebral palsy confused ancient medical practitioners due to its varied clinical picture. In the early to mid$19^{\text {th }}$ century, there were scattered attempts to study and explain the disorder, largely through publications on brain lesions and their clinical manifestations. William Little, an orthopedic surgeon in England, was the first to sincerely engross himself in the study of $\mathrm{CP}$ as a medical disorder [4]. He was born in 1810 in London and developed a clubfoot from either a birth de-

\footnotetext{
*Corresponding author: Kristina M. Stang, Tulane University School of Medicine, 801 Race Street, Apt. 7106, New Orleans, LA 70130, USA. Tel.: +1 630487 8841; E-mail: stang.kristina@ gmail. com.
}

fect or childhood poliomyelitis. He completed his medical studies at the London Hospital in 1828 and later at Guy's Hospital. Little was admitted to the Royal College of Surgeons in 1832 but was unable to secure a position as a surgeon at the London Hospital. He decided to take his talents to Berlin. While in Germany, Little met Luis Stromeyer, a pioneer of tenotomy. In 1836, Stromeyer successfully corrected Little's clubfoot utilizing subcutaneous tenotomy of the Achilles tendon $[4,5]$. Little was inspired by Stromeyer's treatment of his deformity and by his own recovery as a patient, such that he wrote a dissertation on the treatment of foot deformities that earned him a doctoral degree from the University of Berlin in 1837 [4]. Returning to London that year, Little himself performed a tenotomy of an Achilles tendon on a 15-year-old boy, introducing the treatment of deformities into the realm of surgery [5]. He began seeing patients in private practice and by 1839 he published another work specifically on clubfoot treatment. Little's surgical success boosted his reputation as a physician as well as a theorist. In 1840, he finally attained a post at his alma mater London Hospital, his goal since 1832. That same year, he opened the world's first hospital dedicated to treating orthopedic disorders, later known as the Royal Orthopedic Hospital of London [4].

Little continued to cement his reputation as a general physician and clinical instructor [5]. His experiences as both a patient and a doctor, particularly his 
experiences treating young children, resulted in a series of papers published from 1844-1853 [6,7]. He described children with spasticity and stiff extremities - akin to tetanus spasms - as well as paresis and paralysis. Based on his clinical experience, Little began to see a connection between the children's clinical picture and perinatal disorders. Importantly, he made novel connections between bone, joint, and muscle deformities and disorders of the neurological system. He associated the disorders with prematurity, difficult delivery (i.e. via forceps), perinatal asphyxia, and newborn tremors [4]. He began to classify the disorders into groups that are remarkably consistent with modern concepts but were opposite of popular belief at the time [5]. He stated in his 1853 work, "On the Nature and Treatment of the Deformities of the Human Frame," that congenital deformities were divided into two categories that he called "congenital distortions" and "congenital malformations". Congenital distortions were considered the result of derangements of the nervous and muscular systems of the fetus independent of any absence or deficiency of body parts. The distortions were capable of being restored to a "surprising degree of perfection". Congenital malformations, on the other hand, had variable etiologies or were due to a "primary interruption of normal development of fetal parts" and resulted in a total absence, incompleteness, or malformation of organ [7]. Little was also the first to specifically explain the mechanism involved in (spastic) muscular contractures, seen in untreated patients with CP [4]. He noted that permanent muscular contraction can be induced by "longcontinued repose of a limb in the flexed position," due to the gradual shortening of muscles on the flexed side; or by a disorder of the nervous system resulting in the "spastic action of certain muscles of an articulation," due to constant contraction of the muscles that ultimately changes the muscle fibers such that they can no longer be voluntary elongated [7].

Through the years, Little continued to accumulate similar cases with chronic orthopedic problems. His history taking, observational skills, and physical examination technique enabled him to make thoughtful deductions by analyzing birth histories and clinical courses. In fact, Little was one of the first physicians to introduce the taking of birth histories for the field of pediatrics. It was important, he argued, to know details of the pregnancy and labor, whether instruments were used, what the infant's status was at birth, etc., as some could be associated with injury to the brain and spinal cord. All of Little's work pointed increasingly to a singular disorder that accounted for the neurologic deficits seen in all his patients with deformities and intellectual impairments that was distinct from other, better-known diseases at the time such as poliomyelitis $[8,9]$.

As he made more distinctions, Little became aware that surgical treatment of the disease had limitations. Despite his early success and excitement with tenotomies, he eventually became more cautious as he observed that his theoretically corrective treatment often ended up impairing the child's motor function. This idea was especially progressive - as all of Little's conclusions appeared to be at the time - during a time when the efficacy of the field of orthopedics was questioned due to a period of "post-operative disaster", characterized by worse surgical outcomes than anticipated $[4,10]$.

The culmination of Little's maturing thoughts on cerebral palsy was reflected in perhaps his best-known work published in 1861, based on observations and birth histories of over 200 patients [7]. His conviction that $\mathrm{CP}$ was caused by problems during pregnancy and delivery led him to present his ideas to the Obstetrical Society of London that same year; he believed it was necessary that obstetricians knew how important their role was to the future health of a child [9]. Little acknowledged the impact of conditions like placenta previa and prematurity but maintained that $\mathrm{CP}$ was caused by post-partum asphyxia; the distorted blood flow caused lack of oxygen to the brain during delivery resulting in damage that manifested in the clinical picture of $\mathrm{CP}$ that he knew so well [4]. He noted that brain injury could occur in the absence of obvious external trauma, such as bruising, broken bones, visible deformity, etc. [4,9]. Little also detailed different types of paralysis, the possibility of flaccid paralysis, and a link between a degree of paresis and a degree of cognitive impairment, referred to at the time as "mental retardation" [4].

Little's lecture to the Society was 33 pages in print with 20 pages of appendix, covering features of 63 cases. The lecture was long, but powerful and compelling. His audience was stunned. Some agreed that a "novel concept worthy of serious consideration" had been proposed, while other obstetricians argued that they had seen infants with asphyxia who recovered completely. Little conceded that other causes could lead to infantile spastic and paralytic contractions; he even said that "for each congenital case of spasticity, there may be twenty or more from other causes incidental to later life." It is likely that his theory was 
not immediately accepted because obstetricians found his convictions to be farfetched. Plus, they may have balked at the idea that their shortcomings could lead to such significant long-term disabilities [9]. Regardless of the response, Little's 1861 lecture was assuredly a milestone in the history of cerebral palsy. Little resigned from the London Hospital in 1893 but continued performing surgery and conducting research. He was one of the first people to work at the intersection of neurology and orthopedics and his contributions continue to influence both fields [8]. In fact, cerebral palsy was colloquially called "Little's Disease" [8].

The disorder was eventually named cerebral palsy in 1889 by the eminent $20^{\text {th }}$ century Canadian physician William Osler. Osler was a professor of clinical medicine at the University of Pennsylvania who studied neurology. After seeing 151 children with neurologic deformities at the Philadelphia Infirmary for Nervous Diseases, Osler introduced the phrase "cerebral palsy" to the medical field with his monograph titled, "The Cerebral Palsies of Children," published in 1889 [11]. Like Little, Osler attempted to associate birth traumas with the clinical picture of cerebral palsy. He agreed that cerebral palsy usually dates from birth. However, he preferred the hypothesis that trauma leading to meningeal hemorrhage and compression of brain and spinal cord was a major cause of cerebral palsy [9]. Specifically, Osler believed that cerebral palsies arose from destructive lesions to the upper cortico-spinal segment of the motor path, resulting in paralysis with spasm or disordered movements, exaggerated reflexes, neither rapid nor extreme wasting, and normal electrical reactions [11]. He did not make these conclusions alone, acknowledging contributions from German, French, English, and American colleagues [8].

Since the clinical picture varies greatly depending on the nature and extent of the lesion, Osler postulated that it might be preferable to classify the afflictions based on an anatomical or etiological basis. He alluded to the possibility of confusion surrounding the classification of cerebral palsies and instead stated that he would "adhere to custom and classify the cases according to the distribution of the paralysis, whether hemiplegic, diplegic, or paraplegic." The generic term cerebral palsies - the German Cerebrale Kinderlähmung is what he used to arrange his cases [11]. His monograph describes 120 children with hemiplegia and 20 with bilateral hemiplegia. Osler's work provided an excellent classification of cerebral palsy and added significant value to the body of research [9].
Osler, like Little, was interested in the etiology of cerebral palsy. However, despite all his work, Osler maintained that it was nearly impossible to be sure about the causes. This is likely why he focused on providing a comprehensive classification system rather than ruminating excessively on perinatal events that could have caused the trauma he believed damaged the upper motor pathway [9]. Little and Osler guided the body of CP research toward investigating etiological causes of the resultant deformities.

Beliefs on cerebral palsy shifted in 1893 when Austrian Sigmund Freud entered the scene with unique views compared to his contemporaries [8]. Before his well-known career in psychiatry, Freud was passionate about neurology. In 1885 he traveled to France and trained with famed neurologist Jean-Martin Charcot. He would eventually settle in Vienna, where he practiced for the next decade. After studying and writing on neurologic problems in both children and adults, Freud published 3 monographs between 1891 and 1897 as well as many articles on spastic diplegia in children [9].

Freud did not completely stray from the groundwork laid down by others. He agreed largely with Little and stated that some cases of CP might be the result of brain damage from asphyxia, difficult labor, and abnormal parturition. However, noting that an abnormal birth can frequently produce no abnormal effects, Freud believed that diplegia still might be congenital; a difficult birth could be a symptom or result of deeper effects influencing the development of the fetus. He even went on to suggest that a difficult labor and delivery, including asphyxia, might be the result of early developmental defects of the brain rather than the root cause of cerebral palsy. Thus, he dismissed Osler's hypothesis of "spinal pathology" of $\mathrm{CP}$ and decidedly categorized $\mathrm{CP}$ as one of cerebral origin $[8,9]$.

In addition to this ground-breaking pivot in theory, Freud, like Osler, offered a comprehensive classification of CP [9]. Despite being a neuropathologist, Freud preferred to classify $\mathrm{CP}$ using only clinical findings. He believed that the pathological findings in cerebral palsy were from a combination of the initial lesion as well as the repair process. Therefore, pathological findings were only partially related to the clinical manifestation. Freud's classification system combined previously separate categories under the single term "diplegia" for all bilateral disorders, distinct from hemiplegia. Freud found it impossible to try to separate congenital from acquired cases of $\mathrm{CP}$ in some instances; additionally, he thought that separation was generally unhelpful. He also predicted that children 
with ataxic symptoms might require a separate group, but at the time of his research he had not seen enough cases of non-progressive ataxia to be certain [8].

Freud was considered an expert on children's paralytic conditions [9]. His reputation and influence in the scientific community gave serious weight to his assertions regarding the futility of associating the clinical syndrome of CP with neuropathology. It was thought that he may have single-handedly caused the relative scarcity of research about $\mathrm{CP}$ in the first half of the $20^{\text {th }}$ century as a result. This was compounded by the fact that poliomyelitis and tuberculosis were more common causes of disability at the time and likely attracted greater attention from medical researchers. Freud eventually lost interest in cerebral palsy and refocused his energies into the study of psychoanalysis [8]. He did hope that as methods of clinical investigation improved, the diagnosis of $\mathrm{CP}$ would become more precise [3].

The reduced interest in cerebral palsy in the late 1890 's and early $20^{\text {th }}$-century can be partially attributed to pervasive confusion between $\mathrm{CP}$ and poliomyelitis along with a lack of clinical classification and correlation with neuropathology. Progress seemed to have reached an impasse. During this time, $\mathrm{CP}$ was more frequently studied in terms of its management. The technique of lumbosacral dorsal rhizotomy (SDR) to reduce leg spasticity was established by German Otfrid Foerster in 1908. In the United States, individuals like Winthrop Phelps, an orthopedic surgeon in Baltimore, approached CP from an orthopedic point of view. In the 1930's, he developed a treatment regimen mainly concerned with the peripheral muscular skeletal system. He described cerebral birth injuries from an orthopedic perspective rather than a neurological one to facilitate therapy and more successful management of the condition. By the mid-1950's, different hypotheses regarding neurophysiological physiotherapy for the management of CP existed, and quite distinct physiotherapeutic techniques and methods were generated from these hypotheses to treat the movement disability of CP [3].

Attempts to formalize the study of cerebral palsy and clarify the language used to study it gained traction in the late 1950's, partly due to the United States' involvement in World War II, which increased physical medicine's focus on restoring functioning and capability in returning, injured soldiers; this focus was expanded to include those with congenital disabilities such as CP [12]. In the United States, a group of physicians - Earl Carlson, Bronson Crothers, George
Deaver (the sole rehabilitation medicine physician), Temple Fay, Meyer Perlstein, and Winthrop Phelps created the American Academy for Cerebral Palsy (AACP) in 1947 [13]. That was also the year that the field of physiatry and the specialty of physical medicine and rehabilitation (PM\&R) were formally recognized thanks to the efforts of Frank Krusen, Walter Zeiter, and John Coulter. Nearly 80 physicians took the first board exam of the American Board of Physical Medicine, and they continued to make significant contributions to the history of CP research [12]. Notable members of the field in the second half of the $20^{\text {th }}$ century include pediatrician Margaret H. Jones Kanarr and physiatrist Harriet Gillette - some of the first female physicians to serve as presidents of the American Academy for Cerebral Palsy and Developmental Medicine (AACPDM), which expanded its name to reflect wider interest and activity in all disabilities associated with cerebral palsy as well as the full range of developmental disorders [13-15]. Kanarr was especially known for being a pioneer in the treatment of $\mathrm{CP}$, emphasizing the importance of treating speaking, breathing, and swallowing problems in addition to motor issues [16].

In the United Kingdom, "The Little Club," named for CP's original founding father William Little, was formed. Its members included Ronald Mac Keith, Paul Polani, Martin Bax, and Thomas Ingram. These leaders helped drive the concepts and descriptions of $\mathrm{CP}$ forward and encouraged $\mathrm{CP}$ to be the focus of treatment services, advocacy, and research efforts. In 1957 , "The Little Club" met to re-think the terminology that was currently being used. In 1959, they published their best attempt at a definition, that was later reworked it in 1964 by a subset of members [8]. They considered $\mathrm{CP}$ to be "a disorder of posture and movement due to a defect or lesion of the immature brain." Additionally, "for practical purposes disorders of short duration, due to progressive disease or due solely to mental deficiency were excluded [17]." The rework was wellreceived, and its definition became the most frequently cited description of CP. However, that same year, Bax acknowledged that inconsistencies in the field, such as the differing interpretation of terms such as "spastic" between professional and international cultures precluded further progress in defining the disorder. He was quoted as saying that he found it "impossible to proceed definitively with classifying cerebral palsy $[8,17] . "$

While definitive classification of cerebral palsy was not yet universally established, research did not wane 
throughout the second half of the $20^{\text {th }}$ century. The "core" group of early PM\&R physicians interested in children - Angel Badell-Ribera, Gabriella Molnar, and Gloria Eng - published various works on prognosis for ambulation, an important outcome in CP [18-20]. The field of gait analysis and its application to children with CP became popular due to pediatric orthopedic surgeons such Jacqueline Perry and more recently, Jim Gage [21,22].

After years of exposure and research exploring the constellation of motor and sensory impairments that comprise the syndrome of cerebral palsy, a comprehensive definition and suggested classification system were considered at consensus conferences led by Peter Rosenbaum in 2004 in Bethesda, MD (USA). Based on these discussions, the Executive Committee produced a report on the Definition and Classification of Cerebral Palsy in April of 2006 [23]. They differed from previous attempts due to international involvement and inclusion of concepts about impairments, functional status, and participation. According to this definition, "Cerebral palsy describes a group of permanent disorders of the development of movement and posture, causing activity limitation, that are attributed to nonprogressive disturbances that occurred in the developing fetal or infant brain. The motor disorders of CP are often accompanied by disturbances of sensation, perception, cognition, communication, and behavior; by epilepsy, and by secondary musculoskeletal problems." It was recommended that CP be classified based on 4 major dimensions: motor abnormalities, accompanying impairments, anatomical and neuro-imaging findings, and causation and timing. Importantly, the authors stressed that clear-cut categorization by cause is unrealistic at this present time, since $\mathrm{CP}$ may result from the interaction of multiple risk factors or seemingly have no identifiable cause at all. While modern technology allows us to examine neuropathology more, for now the definition of $\mathrm{CP}$ rests on clinical description [23]. This definition is also significant for shifting attention to the International Classification of Functioning, Disability and Health (ICF) framework of activities and expands the ability to classify function [24].

It took nearly 150 years of cerebral palsy research to arrive at this definition. When considering the history of cerebral palsy research and modern medical advances, it is easy to see where researchers like Little, Osler, and Freud went wrong with their theories. Little was unable to determine spinal versus cerebral pathology due to his lack of personal experience in neu- ropathology. He also indicated that most patients with spastic paralysis were intellectually impaired, which is not always the case [9]. Generally, researchers' initial focus was more on etiology, while cerebral palsy is now understood to be a clinically descriptive term rather than an etiologic diagnosis [23]. On the other hand, it is impressive to see what they got right. Little provided an accurate description of the various types of $\mathrm{CP}$, especially spastic diplegia. Freud's claim that abnormal brain development may be the proximate cause of CP in some cases was ahead of his time; his theory was accepted by the medical community nearly 100 years after he first made it [9]. Despite their shortcomings, we must acknowledge the people who have fought diligently to further the scientific study of $\mathrm{CP}$ because they knew how important a quality definition of the diagnosis is. The definition of a diagnosis does not merely identify which cases are to be recorded under that term as well as the ones to exclude; it is the basis for treatment and has epidemiological implications for quantifying the burden of CP. With the inherent variability and uncertainty of $\mathrm{CP}$, it was always clear to researchers that both a diagnosis and classification must be defined if significant progress were to be made in studying it.

The field of cerebral palsy research, diagnosis, and treatment continues to advance. Modern-day cerebral imaging using computed tomography, magnetic resonance imaging, and ultrasound are useful diagnostic tools. Instruments to quantify and monitor developmental milestones and skills and to assess the quality of life of patients and their caregivers are now available [25]. The Gross Motor Function Classification System for Cerebral Palsy (GMFCS), Manual Ability Classification (MAC), Communication Function Classification System (CFCS), Eating and Drinking Ability Classification System (EDACS), and Pediatric Evaluation of Disability Inventory (PEDI) allow for numerical scaling and tracking of patients' functional level and independence [26-28]. The introduction of reliable classification systems for the practice and research of treating children and adults with $\mathrm{CP}$ has had a tremendous impact on the field. Additionally, the ICF framework is now fully infused into the definition and field of $\mathrm{CP}$; it gives practitioners and stakeholders a specific tool with which to explore functioning and disability for assessment, treatment, evaluation, and policy purposes in a global context [29]. Adding to the "common data language" for clinical research studies, cerebral palsy specific Common Data Elements (CDEs) have been developed to increase the 
efficiency and effectiveness of clinical research studies [30]. In addition, individuals such as Paul Gross and Edward Hurvitz have promoted the use of data registries which have emerged to harness the large amount of data that is needed to study a diagnosis with so many variables [31].

Recognizing that there is no cure for $\mathrm{CP}$, the current goal of management is not to achieve normalcy [25]. Childhood disability is now an applied science that focuses on function, family, fun, future, fitness, and friends [32]. The goal is to increase functionality, improve capabilities, and sustain health with respect to locomotion, cognitive development, social interaction and independence [25]. Symptomatic treatment programs involve physical and behavioral therapy, pharmacologic and surgical treatments, mechanical aids, and management of associated medical conditions [25]. As patients with $\mathrm{CP}$ receive better care and survive well into adulthood, individuals like Kevin Murphy and Margaret Turk have responded to this transition out of pediatric care by acting as strong advocates for understanding the aging process and outcomes of adults with CP [33,34].

While we seem to have to successfully defined and classified CP, discussion of it is ongoing. The authors who penned the latest CP definition in 2006 intended for it to be internationally accepted and adopted in order to provide a broad spectrum of audiences with a common conceptualization of cerebral palsy. The definition is based essentially on clinical aspects, although operationally defining each characteristic is a challenge. For example, similarly to Bax's 1964 observations of the term "spastic", as of 2006 the term "spastic diplegia" was problematic due to the variability and imprecision of circulating definitions. The utility and reliability of the classification scheme presented in 2006 is dependent on how the users are implementing it [23].

Future work will shed more light on the various pathologic processes and clinical manifestations that currently comprise CP. Until then, we can appreciate and respect the progress that has been made in obstetrics, pediatrics, neurology, and rehabilitation therapies regarding CP since Pharaoh Siptah's tomb was uncovered and Little first introduced the disorder to the medical field. Work continues to improve functional skills and movement, participation, and quality of life for those with $\mathrm{CP}$; the creation of subspecialties within PM\&R, like pediatric rehabilitation medicine and neuromuscular medicine, now provide specific pathways for training [35]. The past has shown us that many con- tribute to the understanding of $\mathrm{CP}$; the future of $\mathrm{CP}$ research is sure to continue fostering and encouraging young collaborative talent. While the story of CP has involved many key and eminent individuals, there is more work to be done!

\section{Conflict of interest}

The authors have no conflicts of interest to report. No funding was received in the making of this manuscript.

\section{References}

[1] The Oxford History of Ancient Egypt. Shaw I, editor: Oxford University Press 2000. p. 512.

[2] KV 47 (Siptah) - Theban Mapping Project. Available from http://www.thebanmappingproject.com/sites/browse_tomb_ 861.html.

[3] Panteliadis C, Panteliadis P, Vassilyadi F. Hallmarks in the history of cerebral palsy: from antiquity to mid-20th century. Brain Dev. 2013; 35(4): 285-92. doi: 10.1016/j.braindev. 2012.05.003.

[4] Pietrzak K, Grzybowski A, Kaczmarczyk J. William john little (1810-1894). J Neurol. 2016; 263(5): 1047-9. doi: 10 1007/s00415-015-7890-5.

[5] Dunn PM. Dr william little (1810-1894) of London and cerebral palsy. Arch Dis Child Fetal Neonatal Ed. 1995; 72(3): F209-10. doi: 10.1136/fn.72.3.f209.

[6] Little WJ. Course of lectures on the deformities of the human frame. The Lancet. 1844; 41(1072): 809-15.

[7] Little WJ. On the nature and treatment of deformities of the human frame. London: Longman, Brown, Green and Longmans; 1853.

[8] Morris C. Definition and classification of cerebral palsy: a historical perspective. Dev Med Child Neurol Suppl. 2007; 109: 3-7.

[9] Raju TNK. Historical perspectives on the etiology of cerebral palsy. Clin Perinatol. 2006; 33(2): 233-50. doi: 10.1016/j.clp. 2006.03.006.

[10] Eggers GWN, Evans EB. Surgery in cerebral palsy. J Bone Joint Surg Am. 1963; 45: 1275-305.

[11] Osler W. The Cerebral Palsies of Children: A Clinical Study from the Infirmary for Nervous Diseases, Philadelphia London: H.K. Lewis; 1889.

[12] History of the Specialty [About Physiatry: History of the Specialty]. Available from: https://www.aapmr.org/about-physiat ry/history-of-the-specialty.

[13] 60 Years of the American Academy for Cerebral Palsy and Developmental Medicine [updated September 2, 2016]. Available from: https://www.aacpdm.org/about/history.

[14] American Academy for Cerebral Palsy and Developmental Medicine: Past \& Future Presents. Available from: https:// www.aacpdm.org/UserFiles/file/PastPresidents.pdf.

[15] Gillette HE. Presidential address to the american academy for cerebral palsy. Dev Med Child Neurol. 1971; 13(4): 533-5.

[16] In Memoriam: Margaret H. Jones. Available from: https:// senate.universityofcalifornia.edu/_files/inmemoriam/html/ MargaretH.Jones.htm. 
[17] Bax MC. Terminology and classification of cerebral palsy. Dev Med Child Neurol. 1964; 6: 295-7.

[18] Badell-Ribera A. Cerebral palsy: postural-locomotor prognosis in spastic diplegia. Arch Phys Med Rehabil. 1985; 66(9): 614-9.

[19] Molnar GE, Gordon SU. Cerebral palsy: predictive value of selected clinical signs for early prognostication of motor function. Arch Phys Med Rehabil. 1976; 57(4): 153-8.

[20] Binder H, Eng GD. Rehabilitation management of children with spastic diplegic cerebral palsy. Arch Phys Med Rehabil. 1989; 70(6): 482-9.

[21] Hoffer MM, Perry J. Pathodynamics of gait alterations in cerebral palsy and the significance of kinetic electromyography in evaluating foot and ankle problems. Foot Ankle. 1983; 4(3): 128-34.

[22] Novacheck TF, Gage JR. Orthopedic management of spasticity in cerebral palsy. Childs Nerv Syst. 2007; 23(9): 1015-31. doi: 10.1007/s00381-007-0378-6.

[23] Rosenbaum P, Paneth N, Leviton A, Goldstein M, Bax M, Damiano D, et al. A report: the definition and classification of cerebral palsy April 2006. Dev Med Child Neurol Suppl. 2007; 109: 8-14.

[24] International Classification of Functioning, Disability and Health (ICF). Geneva: World Health Organization; 2001

[25] Krigger KW. Cerebral palsy: an overview. Am Fam Physician. 2006; 73(1): 91-100.

[26] Paulson A, Vargus-Adams J. Overview of four functional classification systems commonly used in cerebral palsy. Children (Basel). 2017; 4(4). doi: 10.3390/children4040030.

[27] Sellers D, Pennington L, Mandy A, Morris C. A systematic review of ordinal scales used to classify the eating and drinking abilities of individuals with cerebral palsy. Dev Med Child Neurol. 2014; 56(4): 313-22. doi: 10.1111/dmcn.12313.
[28] Vargus-Adams JN, Martin LK, Maignan SH, Klein AC, Salisbury $\mathrm{S}$. The GMFM, PEDI, and CP-QOL and perspectives on functioning from children with $\mathrm{CP}$, parents, and medical professionals. J Pediatr Rehabil Med. 2011; 4(1): 3-12. doi: 10.3233/PRM-2011-0148.

[29] Schiariti V, Longo E, Shoshmin A, Kozhushko L, Besstrashnova $\mathrm{Y}$, Krol M, et al. Implementation of the International Classification of Functioning, Disability, and Health (ICF) Core Sets for Children and Youth with Cerebral Palsy: Global Initiatives Promoting Optimal Functioning. Int J Environ Res Public Health. 2018; 15(9). doi: 10.3390/ijerph15091899.

[30] Schiariti V, Fowler E, Brandenburg JE, Levey E, McIntyre S, Sukal-Moulton T, et al. A common data language for clinical research studies: the national institute of neurological disorders and stroke and american academy for cerebral palsy and developmental medicine cerebral palsy common data elements version 1.0 recommendations. Dev Med Child Neurol. 2018; 60(10): 976-86. doi: 10.1111/dmcn.13723.

[31] Gross PH, Bailes AF, Horn SD, Hurvitz EA, Kean J, Shusterman M, et al. Setting a patient-centered research agenda for cerebral palsy: a participatory action research initiative. Dev Med Child Neurol. 2018; 60(12): 1278-84. doi: 10.1111/ dmen.13984.

[32] Rosenbaum P, Gorter JW. The 'F-words' in childhood disability: I swear this is how we should think! Child Care Health Dev. 2012; 38(4): 457-63. doi: 10.1111/j.1365-2214.2011. 01338.x.

[33] Murphy KP. The adult with cerebral palsy. Orthop Clin North Am. 2010; 41(4): 595-605. doi: 10.1016/j.ocl.2010.06.007.

[34] Turk MA. Health, mortality, and wellness issues in adults with cerebral palsy. Dev Med Child Neurol. 2009; 51(Suppl 4): 24 9. doi: 10.1111/j.1469-8749.2009.03429.x.

[35] American Board of Physical Medicine and Rehabilitation Subspecialty Certification. Available from: https://www.abp mr.org/Subspecialties. 